\title{
Article
}

\section{Autotune Identification under Load Disturbance}

Shih-Haur Shen, Jiun-Sheng $\mathrm{Wu}$, and Cheng-Ching Yu

Ind. Eng. Chem. Res., 1996, 35 (5), 1642-1651 • DOI: 10.1021/ie950480g

Downloaded from http://pubs.acs.org on November 28, 2008

\section{More About This Article}

Additional resources and features associated with this article are available within the HTML version:

- $\quad$ Supporting Information

- $\quad$ Links to the 4 articles that cite this article, as of the time of this article download

- $\quad$ Access to high resolution figures

- $\quad$ Links to articles and content related to this article

- Copyright permission to reproduce figures and/or text from this article

\section{View the Full Text HTML}

\section{ACS Publications}




\title{
Autotune Identification under Load Disturbance
}

\author{
Shih-Haur Shen, J iun-Sheng Wu, and Cheng-Ching Yu*
}

Department of Chemical Engineering, National Taiwan Institute of Technology, Taipei, Taiwan 106, R.O.C.

Frequent and large load changes are often encountered in chemical processes. This can be lead to erroneous results in system identification especially for the fully automated identification procedure in autotuners. Relatively speaking, the relay feedback test is less sensitive to load disturbance (e.g., as compared to the step test). However, as the magnitude of load increases, the estimates of ultimate gain and ultimate frequency deteriorate exponentially. In this work, the causes of errors are analyzed using a describing function and a remedial action is devised. Since load disturbance leads to asymmetric output responses, an output-biased relay is employed to restore symmetric output response. Furthermore, instead of a trial-and-error procedure, the bias value can be calculated immediately following system responses. Subsequently, an identification procedure is proposed to maintain the quality of the model in the face of load changes. Linear and nonlinear systems are used to test the effectiveness of the proposed procedure. The results show that the proposed approach maintains the quality of estimates under step-like and non-step-like load changes.

\section{Introduction}

Finding a dynamic model for the purpose of control is an important step in process control. This leads to the control-relevant identification (Rivera et al., 1992; Shook et al., 1992). In addition to the control-relevant feature, another trend in system identification is that the identification procedure should be as fully automated as possible. This can be seen from the new line of autotuners offered by the vendors (Hang et al., 1993b; Åström and Hägglund, 1995). In other words, the automatic tuning al most becomes a standard feature (or an option) in PID controllers. Therefore, an automated identification procedure can be found in these controllers. Two methods are widely used in these autotuners. One is the step response method (Seborg et al., 1989; Marlin, 1995), where a step change is made in the manipulated variable and a process model is identified from system responses (e.g., method of process reaction curve). This is a straightforward and physically appealing approach for system identification. However, the qual ity of the model can be strongly affected by load disturbances and/or process nonlinearity. Therefore, some kind of model validation step is generally recommended to ensure the accuracy of the identified model (Marlin, 1995). Another popular approach employed in a commercial autotuner is the relay feedback test (Åström and Hägglund, 1984; Luyben, 1987; Hang et al., 1993b; Friman and Waller, 1994; Shen and Yu, 1994), where continuous cycling is generated under a controlled condition (the magnitude of oscillation is controlled by the users). The relay feedback test finds an important point on the Nyquist curve, ultimate gain $\left(K_{\mathrm{u}}\right)$, and ultimate frequency $\left(\omega_{\mathrm{u}}\right)$, and the information can further be utilized to backcalculate parameters for a process model. The advantage of this approach is that it finds the familiar process information $\left(\mathrm{K}_{\mathrm{u}}\right.$ and $\left.\omega_{\mathrm{u}}\right)$ (e.g., for Ziegler-Nichols type of tuning; Ziegler and Nichols, 1942) in a controllable manner. Relatively speaking, the relay feedback based approaches are less sensitive to load disturbance, since the closed-loop characteristic equation is not affected by load changes. However, the biased oscillation deteriorates the esti-

* To whom all correspondence should be addressed. Email: ccyu@ch.ntit.edu.tw. Fax: +886-2-737-6644. mate of $\mathrm{K}_{\mathrm{u}}$ and $\omega_{\mathrm{u}}$. Hang et al. (1993a) propose the use of a biased (displaced) relay feedback test (Luyben and Eskinat, 1994; Wu et al., 1994; Shen et al., 1995) to overcome static input-side load disturbance. However, a trial-and-error procedure is needed to establ ish symmetric oscillation. This can lead to a much longer period of time for the plant experiment.

Since frequent and large load changes are often encountered in chemical processes, any automated system identification procedure should be able, at least, to detect load changes or, more positively, to find quality process information under load disturbance. The objective of this work is to devise an identification procedure which can take the load effect into account throughout the plant test. In other words, instead of analyzing or validating the plant data afterward, the load effect is compensated during the plant experiment. This paper is organized as follows. The effects of load changes on different identification methods are analyzed in section 2. The describing function is employed to analyze the load effect and output-biased relay, and a new result is derived for the bias value adjustment in section 3 . Consequently, an identification procedure is proposed to overcome load disturbance. In section 4, a linear system and a nonlinear distillation column system are used to test the effectiveness of the proposed procedure, followed by the conclusion.

\section{Problems}

Disturbance rejection is the major consideration in chemical process control. In terms of control, the slow chemical processes have to overcome frequent and progressive types of load changes. Facing frequent load changes, any reliable identification methodology should be as insensitive to load change as possible. Therefore, sensitivity with respect to load changes is an important criterion in evaluating identification techniques.

2.1. Step Change versus Continuous Cycling. Two popular identification methods, the step test and relay feedback test, are compared. Consider a secondorder linear system with the process transfer function $\left(\mathrm{G}_{2}(\mathrm{~s})\right)$ :

$$
G_{2}(s)=\frac{e^{-2 s}}{(10 s+1)(s+1)}
$$




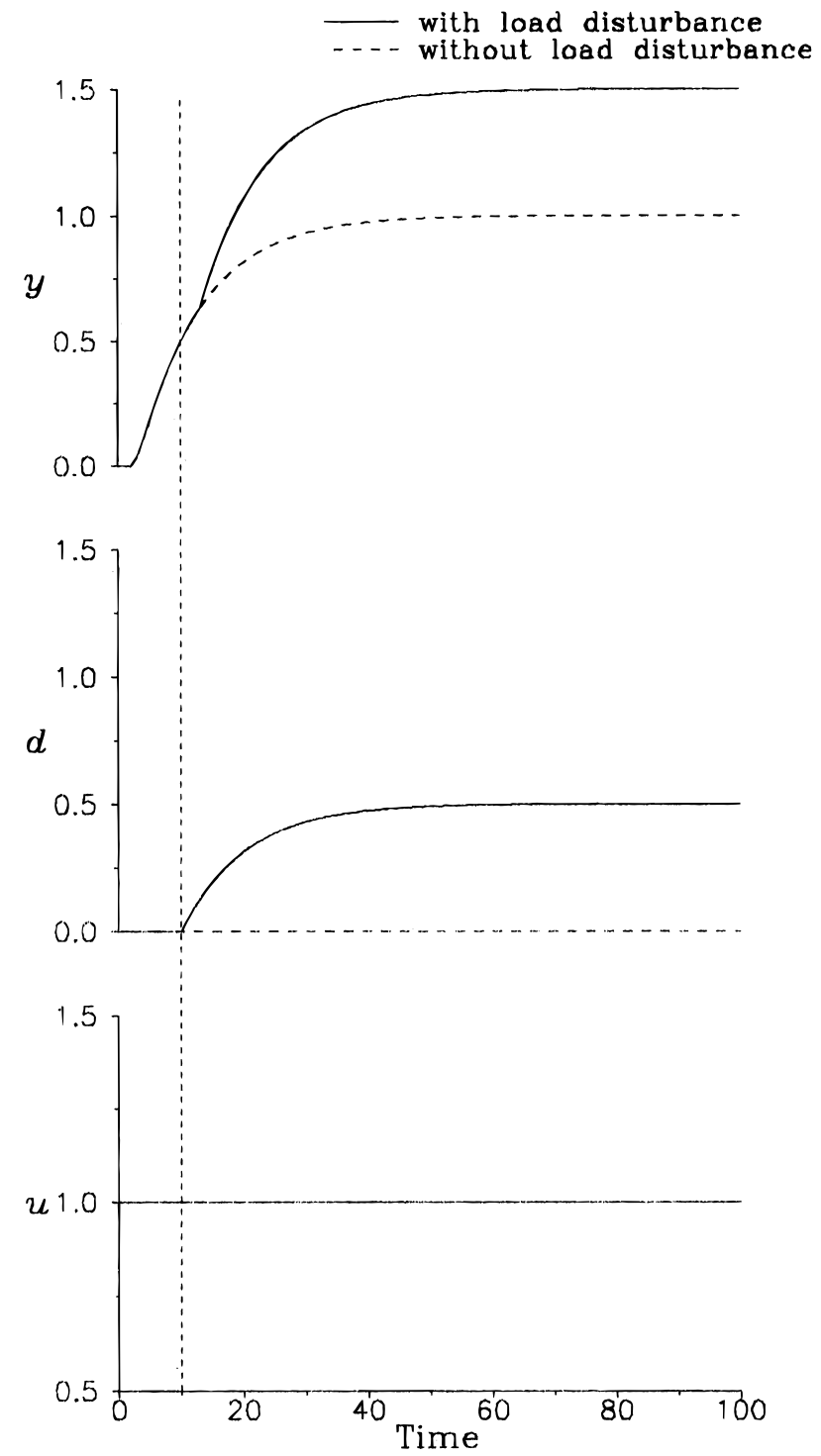

Figure 1. Step test for $\mathrm{G}_{2}(\mathrm{~s})$ with and without load disturbance.

The load comes in on the output side with the transfer function:

$$
G_{L}(s)=\frac{e^{-s}}{(10 s+1)}
$$

First, a step test is introduced and the step response is shown in Figure 1. From the system input $(u)$ and output (y), the reaction curve method (Smith, 1972; Seborg et al., 1989, p 175) is used to find a second-order plus dead time model. The result gives

$$
\hat{\mathrm{G}}_{2}(\mathrm{~s})=\frac{\mathrm{e}^{-2 \mathrm{~s}}}{(9.4 \mathrm{~s}+1)(0.86 \mathrm{~s}+1)}
$$

The errors in the time constants come from small errors in reading off $20 \%$ and $60 \%$ step responses. From the identified model $\hat{G}_{2}(\mathrm{~s})$, the ultimate gain $\left(\mathrm{K}_{\mathrm{u}}\right)$ and ultimate frequency $\left(\omega_{\mathrm{u}}\right)$ are $\mathrm{K}_{\mathrm{u}}=6.749$ and $\omega_{\mathrm{u}}=0.6237$. This corresponds to $-4.5 \%$ error in $\mathrm{K}_{u}$ and $3.95 \%$ error in $\omega_{\mathrm{u}}$, respectively. Actually, a fairly good model is found from the process reaction curve. However, if a step load change $(L=0.5)$ comes in at $t=10 \mathrm{~min}$, the step response is distorted as shown in Figure 1 (solid line). Again, Smith's method is employed to find the
Ind. Eng. Chem. Res., Vol. 35, No. 5, 1996

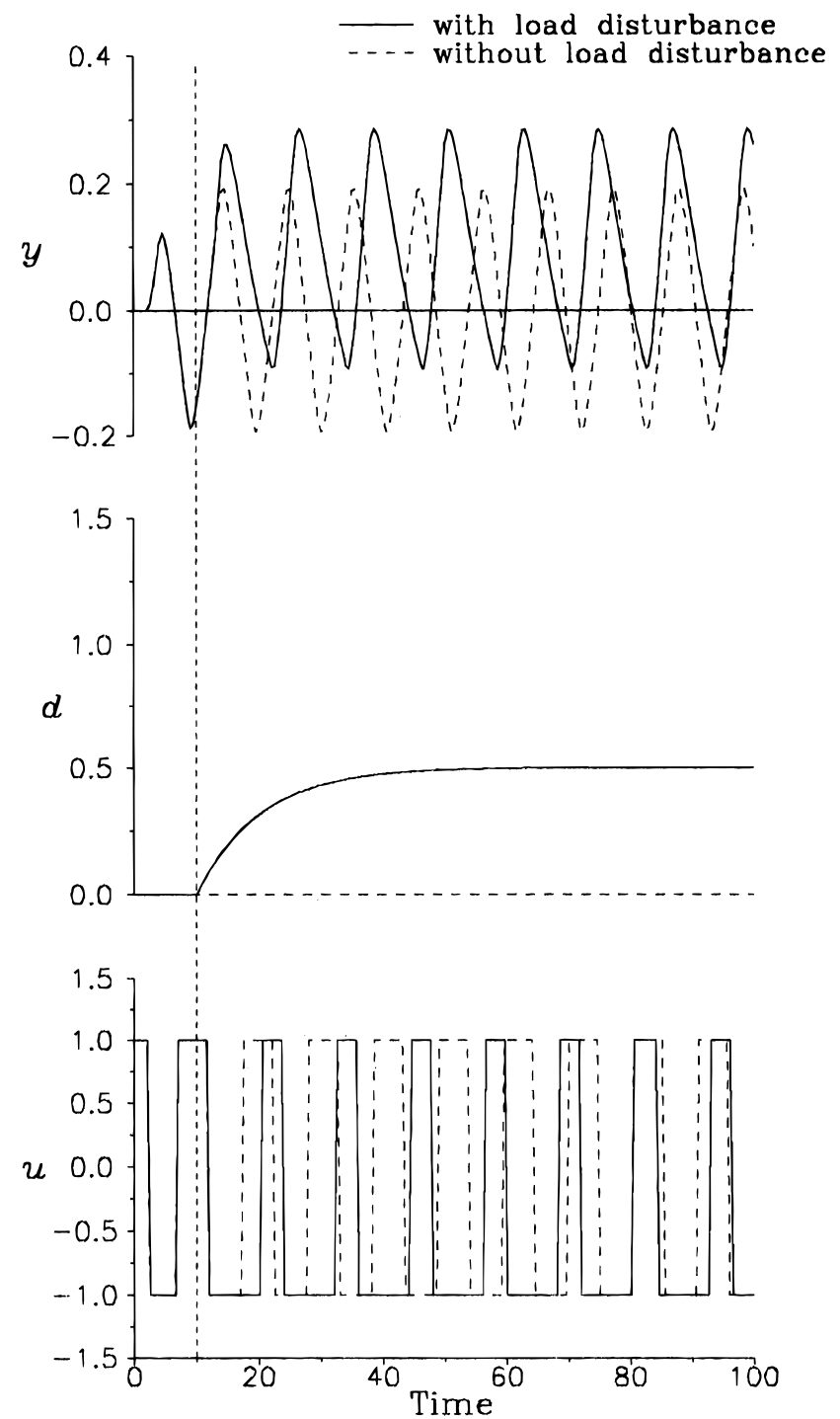

Figure 2. Relay feedback test for $\mathrm{G}_{2}(\mathrm{~s})$ with and without load disturbance.

transfer function. It becomes

$$
\hat{\mathrm{G}}_{2}(\mathrm{~s})=\frac{1.5 \mathrm{e}^{-2 \mathrm{~s}}}{(8 \mathrm{~s}+1)(2.3 \mathrm{~s}+1)}
$$

From the identified model ( $\hat{G}_{2}(\mathrm{~s})$ in eq 4$)$, it is quite clear that the quality of the model deteriorates significantly. This corresponds to $-42.7 \%$ and $-18.3 \%$ errors in $\mathrm{K}_{\mathrm{u}}$ and $\omega_{\mathrm{u}}$, respectively. Furthermore, the deviation can become even greater if the magnitude of load change increases.

An alternative is the relay feedback test, where an ideal relay is placed in the feedback loop to generate sustained oscillation. From system responses, the important information, ultimate gain $\left(\mathrm{K}_{\mathrm{u}}\right)$ and ultimate frequency $\left(\omega_{\mathrm{u}}\right)$, can be found. That gives

$$
\begin{aligned}
& \mathrm{K}_{\mathrm{u}}=4 \mathrm{~h} / \pi \mathrm{a} \\
& \omega_{\mathrm{u}}=2 \pi / \mathrm{P}_{\mathrm{u}}
\end{aligned}
$$

where $h$ is the height of the relay and $a$ is the amplitude of the output response. Notice that the estimates of $\mathrm{K}_{\mathrm{u}}$ and $\omega_{\mathrm{u}}$ come from the principal harmonic approximation of a nonlinear response (e.g., $u$ in Figure 2). Figure 2 shows the input and output responses, and $\mathrm{K}_{\mathrm{u}}$ and $\omega_{\mathrm{u}}$ 
(A)

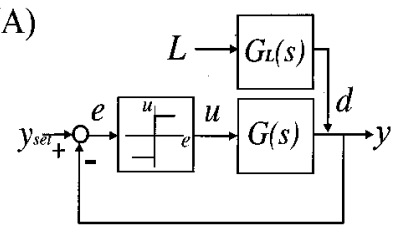

(B)

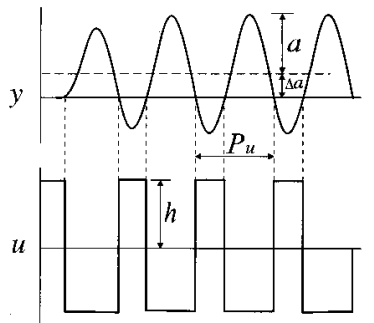

Figure 3. I deal relay feedback system under load disturbance: (A) block diagram; (B) system input and output responses.

can be calculated from eqs 5 and 6 . That gives $K_{u}=$ 6.55 and $\omega_{\mathrm{u}}=0.5978$, which corresponds to $-7.36 \%$ and $-0.11 \%$ errors in $\mathrm{K}_{\mathrm{u}}$ and $\omega_{\mathrm{u}}$, respectively. Again, a load change with $L=0.5$ is introduced at $t=10 \mathrm{~min}$ (solid line in Figure 2). From system responses, two observations become apparent. First, the system output is asymmetric ( $y$ is asymmetric with respect to the set point). The second observation is that the offset in $y$ is not equal to the magnitude of the load effect (d) (Figure 2). For this asymmetric oscillation, the amplitude of the oscillation, a, is taken as the average of the oscillation:

$$
\mathrm{a}=\frac{\mathrm{y}^{\max }-\mathrm{y}^{\min }}{2}
$$

where $y^{\max }$ and $y^{\min }$ stand for the maximum and minimum values of process output, respectively. Despite the presence of the load disturbance, the resultant estimates of $\mathrm{K}_{\mathrm{u}}$ and $\omega_{\mathrm{u}}$ are still quite reliable and corresponding errors in $\mathrm{K}_{\mathrm{u}}$ and $\omega_{\mathrm{u}}$ are $-7.14 \%$ and $-13.1 \%$, respectively.

The results clearly indicate that continuous cycling using an ideal relay feedback is more robust with respect to load change as compared to the method of the step test. This can be understood since the limit of stability is invariant under bounded load changes.

2.2. Effect of Load Change on the Relay Feedback Test. Despite the fact that the relay feedback test is less sensitive to load disturbances, the estimates of $\mathrm{K}_{\mathrm{u}}$ and $\omega_{\mathrm{u}}$ (in particular) also deteriorate slightly for a moderate load change $(L=0.5)$. Unfortunately, the errors in the estimates of $K_{u}$ and $\omega_{u}$ grow exponentially as the magnitude of the load change increases. Let us take three typical linear transfer functions to illustrate the effect of load disturbance.

Consider an ideal relay feedback system with an external load variable L (Figure 3A). Under load disturbance, an ideal relay feedback test results in an asymmetric oscillation as shown in Figure 3B. In addition to the second-order plus dead time system $\left(\mathrm{G}_{2^{-}}\right.$ (s) in eq 1), a first-order and a third-order plus dead time system are considered.

$$
G_{1}(s)=\frac{e^{-2 s}}{(10 s+1)}
$$

and

$$
\mathrm{G}_{3}(\mathrm{~s})=\frac{\mathrm{e}^{-2 \mathrm{~s}}}{(20 \mathrm{~s}+1)(10 \mathrm{~s}+1)(\mathrm{s}+1)}
$$

with a load transfer function $G_{\mathrm{L}}$ (s) (eq 2). I deal relay feedback tests with $\mathrm{h}=1$ are performed on these three examples for a wide range of load changes. $\mathrm{K}_{\mathrm{u}}$ and $\omega_{\mathrm{u}}$ (or $\mathrm{P}_{\mathrm{u}}$ ) are computed from system input-output responses, and the results show that estimated errors, $\omega_{\mathrm{u}}$ in particular, grow exponentially as the magnitude of load increases (Figure 4). F urthermore, the consistencies in the estimate of $\mathrm{K}_{\mathrm{u}}$ deteri orate as the order of the system increases. Since load disturbance is uncontrollable in an operating environment, a remedial action has to be taken to ensure the quality of the identified model.

\section{Analyses}

3.1. Sources of Errors. An ideal relay feedback test under a step load change gives asymmetric output responses (y in Figure 3), and, consequently, the imbalance in half-periods results. This asymmetry as well as the imbalance leads to errors in the estimates of $\mathrm{K}_{\mathrm{u}}$ and $\omega_{\mathrm{u}}$.

Unlike a simple relay feedback system $(L=0$ in Figure $3 \mathrm{~A}$ ), the input to the nonlinear el ement consists of two elements: a symmetric oscillation and a step input. This type of problem are known to the control community as the dual input describing function (DIDF) as early as the 1950s (West et al., 1956). In order to describe the characteristics of the nonlinear element (an ideal relay), the relationship between the input and output signals of the nonlinear element can be separated into two parts: one is the oscillatory part (the gain of the sinusoidal wave to the output of the nonlinear element) and the other one is the static part (the gain of the biased signal to the output of the nonlinear element). The static part can be described by the equivalent gain (Oldenburger and Boyer, 1962):

$$
\mathrm{N}_{\gamma}=\overline{\mathrm{u}} / \mathrm{e}
$$

where $\bar{u}$ and $\bar{e}$ are the averaged output and input of the nonlinear element which can be found by integrating system response. For example:

$$
\begin{aligned}
& \bar{u}=\frac{1}{P_{u}} \int_{t}^{P_{u}+t} u(t) d t \\
& \bar{e}=\frac{1}{P_{u}} \int_{t}^{P_{u}+t} e(t) d t
\end{aligned}
$$

The oscillatory part is characterized by the familiar describing function $\mathrm{N}(\mathrm{a})$. The following conditions should be satisfied for the existence of sustained oscillation (Atherton, 1982).

$$
\begin{gathered}
\overline{\mathrm{e}}\left(1+\mathrm{N}_{\gamma} \mathrm{G}(0)\right)=-\mathrm{G}_{\mathrm{L}}(0) \mathrm{L} \\
1+\mathrm{NG}(\mathrm{j} \omega)=0
\end{gathered}
$$

Equations 13 and 14 give constraint at the low (zero) frequency (eq 13) and the high $\left(\omega=\omega_{\mathrm{u}}\right)$ frequency. Furthermore, eq 13 relates the bias in the output (e) to the external load disturbance $\left(G_{L} L\right)$.

The describing function analysis shows the difference between a simple relay and a relay feedback under load change. Considering a relay feedback system (Figure 3 ), the output $(\mathrm{u}(\mathrm{t}))$ of the nonlinear element can be 


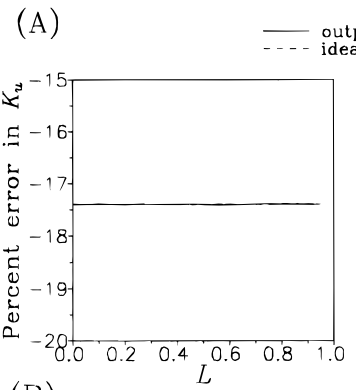

(B)

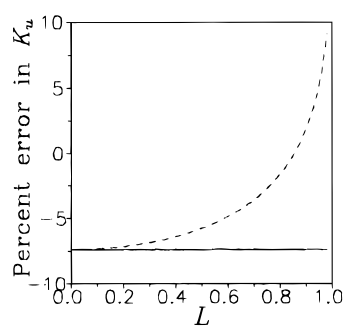

(C)

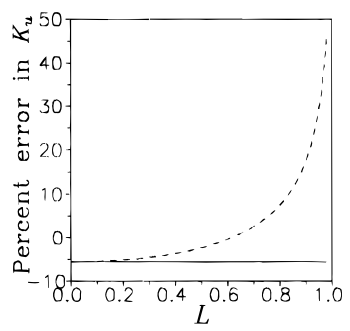

Figure 4. Percent error in $\mathrm{K}_{\mathrm{u}}$ and $\omega_{\mathrm{u}}$ under load changes for ideal and output-biased relay feedback systems: (A) first-order model $\left(\mathrm{G}_{1}\right)$; $(\mathrm{B})$ second-order model $\left(\mathrm{G}_{2}\right)$; $(\mathrm{C})$ third-order model $\left(\mathrm{G}_{3}\right)$.

expressed in terms of the Fourier series:

$$
u(t)=A_{0}+\sum_{n=1}^{\infty}\left(A_{n} \cos n \omega t+B_{n} \sin n \omega t\right)
$$

where

$$
\begin{gathered}
A_{0}=\frac{1}{2 \pi} \int_{0}^{2 \pi} u(t) d \omega t \\
=-\frac{2 h}{\pi} \sin ^{-1}\left(\frac{\Delta a}{a}\right) \\
A_{n}=\frac{1}{\pi} \int_{0}^{2 \pi} u(t) \cos n \omega t d \omega t \\
=\frac{4 h}{n \pi} \sin \left[n \sin ^{-1}\left(\frac{\Delta a}{a}\right)\right], \quad n=2,4,6, \ldots \\
B_{n}=\frac{1}{\pi} \int_{0}^{2 \pi} u(t) \sin ^{n} \omega t d \omega t \\
=\frac{4 h}{n \pi} \cos \left[n \sin ^{-1}\left(\frac{\Delta a}{a}\right)\right], \quad n=1,3,5, \ldots
\end{gathered}
$$

The factor $A_{0}$ describes the imbalance in the halfperiods. Furthermore, in addition to the well-known terms $B_{1}, B_{3}, B_{5}, \ldots$ from a single-input system $(L=0)$, the dual-input system $(L \neq 0)$ gives the following nonzero terms: $A_{2}, A_{4}, A_{6}, \ldots$ It is quite clear that the term describing the imbalance, $A_{0}$, and the additional terms, $A_{2}, A_{4}, A_{6}$, etc., deteriorate the principal harmonic approximation and, subsequently, lead to erroneous estimates of $\mathrm{K}_{\mathrm{u}}$ and $\omega_{\mathrm{u}}$. F urthermore, if $\Delta \mathrm{a}$ approaches

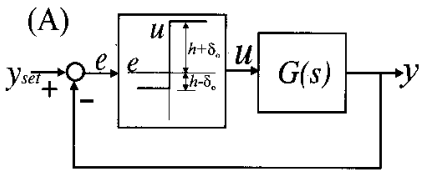

(B)

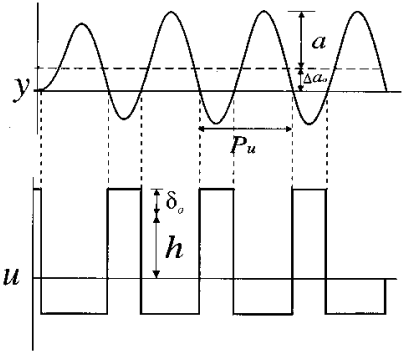

Figure 5. Output-biased relay feedback system: (A) block diagram; (B) system input and output responses.

zero, the $A_{0}, A_{2}, A_{4}, \ldots$ terms disappear. Notice that the asymmetric output response can also be observed from a relay feedback under a disturbance-free condition (Figure 5). Figure 5A shows an output-biased relay with a bias value $\delta_{0}$. The system response indicates an asymmetrical oscillation with respect to the set point $(y=0)$, and the imbalance in half-periods is also observed (Figure 3). It, then, becomes obvious that we can utilize the asymmetry ( $\Delta \mathrm{a}_{0}$ in Figure $\left.5 \mathrm{~B}\right)$ of the output-biased relay to cancel out the asymmetry ( $\Delta a$ in Figure 3B) generated from a load change.

3.2. Output-Biased Relay Feedback System. Before getting into the detail of restoring symmetry, the frequency response of the output-biased relay is analyzed. Considering an output-biased relay feedback system (output bias), the output of nonlinear element $\mathrm{u}$ (Figure 5) can be expressed in terms of Fourier coefficients. That is:

$$
\begin{aligned}
A_{0} & =\frac{1}{2 \pi} \int_{0}^{2 \pi} u(t) d \omega t \\
& =-\frac{2 h}{\pi} \sin ^{-1}\left(\frac{\Delta a_{0}}{a}\right)-\delta_{0}
\end{aligned}
$$

$$
\begin{aligned}
A_{n} & =\frac{1}{\pi} \int_{0}^{2 \pi} u(t) \cos n \omega t d \omega t \\
& =\frac{4 h}{n \pi} \sin \left[n \sin ^{-1}\left(\frac{\Delta a_{0}}{a}\right)\right], \quad n=2,4,6, \ldots \\
B_{n} & =\frac{1}{\pi} \int_{0}^{2 \pi} u(t) \sin n \omega t d \omega t \\
& =\frac{4 h}{n \pi} \cos \left[n \sin ^{-1}\left(\frac{\Delta a_{0}}{a}\right)\right], \quad n=1,3,5, \ldots
\end{aligned}
$$

Equations 19-21 show all nonzero terms in the F ourier expansion. Except for the biased term (eq 19), Fourier coefficients describing the oscillatory part (eqs 20 and 21) are exactly the same as that from load disturbance (eqs 17 and 18).

Let us first consider an ideal relay feedback system. If a load disturbance is introduced, the output oscillation is biased with a value of $\Delta a$ (Figure 3 ). If the relay block is switched to an output-biased relay (e.g., Figure 5A), with an appropriate adjustment of $\delta_{0}$, it is possible to eliminate the asymmetry in the output oscillation. That implies, under a static load change, we can have an output-biased relay feedback system with a symmetric output response. Under this circumstance $\left(\Delta \mathrm{a}_{0}=0\right)$, 
eqs 20 and 21 become:

$$
\begin{gathered}
A_{n}=0, \quad n=2,4,6, \ldots \\
B_{n}=4 h / n \pi, \quad n=1,3,5, \ldots
\end{gathered}
$$

and the principal harmonic approximation gives the following describing function $\mathrm{N}(\mathrm{a})$ :

$$
N(a)=4 h / \pi a
$$

It should be emphasized that eq 24 is exactly the same as the describing function for the disturbance-free case. More importantly, performance degradation (in the estimates of $\mathrm{K}_{\mathrm{u}}$ and $\omega_{\mathrm{u}}$ ) can be eliminated. Figure 4 (solid line) clearly shows that the output-biased relay feedback retains the quality of the estimates for a wide range of load changes. Similar to the work of Hang $(1993 a, b)$, the correct biased value comes from a trialand-error procedure.

In an operating condition, it is not practical to have an on-line trial-and-error procedure, since this can prolong the duration time for a plant test. Therefore, it is desirable to devise a procedure in which the biased value $\left(\delta_{0}\right)$ can be found efficiently.

3.3. Derivation of the Biased Value $\left(\delta_{0}\right)$. 3.3.1. Effect of Load Disturbance. Before finding an appropriate $\delta_{0}$ to overcome load effect, one has to analyze the relationship between the output bias $(\Delta a)$ and load effect from available process information. From the literature, one possibility is the static relationship describing the existence of a sustained oscillation (eq 13). That is:

$$
\overline{\mathrm{e}}\left(1+\frac{\overline{\mathrm{u}}}{\overline{\mathrm{e}}} \mathrm{K}_{\mathrm{p}}\right)=-\mathrm{K}_{\mathrm{L}} \mathrm{L}
$$

where $\bar{e}$ and $\bar{u}$ can be found from integrating system output and input responses and $K_{p}$ and $K_{L}$ stand for steady-state gains for the process and load transfer functions, respectively. Unfortunately, eq 25 gives two unknowns $K_{p}$ and $K_{L} L$ which cannot be solved explicitly. Furthermore, $\Delta a$ is not involved in the equation.

A new relationship describing $\Delta a$ and load effect $K_{L} L$ is derived. Let us analyze two extreme conditions for the existence of sustained oscillation. The asymmetry in the output $(\Delta a)$ arises from the $A_{0}$ term (eq 16) according to the Fourier expansion. Therefore, the two cases are classified as the lower and upper bounds of $\Delta a$ under the condition for the existence of a limit cycle. Consider the feedback loop in Figure 3.

(1) Lower Bound $(\Delta \mathbf{a}=\mathbf{0})$. The lower bound for $\Delta \mathrm{a}$ is quite obvious. That is, $\Delta \mathrm{a}=0$. The corresponding load effect is

$$
\mathrm{K}_{\mathrm{L}} \mathrm{L}=0
$$

This can be understood from the typical symmetric oscillation obtained from an ideal relay feedback when load disturbance does not exist (symmetric inputoutput response is an indicati on of zero load effect). This can also be understood by analyzing F ourier coefficients (eqs 16-18). If $\Delta a=0$, the bias term $A_{0}$ (eq 16) disappears, and this implies the disturbance-free case.

(2) Upper Bound $(\Delta \mathbf{a} \rightarrow \mathbf{a})$. Another extreme is when $\Delta \mathrm{a}$ approaches the amplitude of the output oscillation (Figure 3B). (Notice that we cannot have a $\Delta a$ that exceeds the amplitude a and still has a
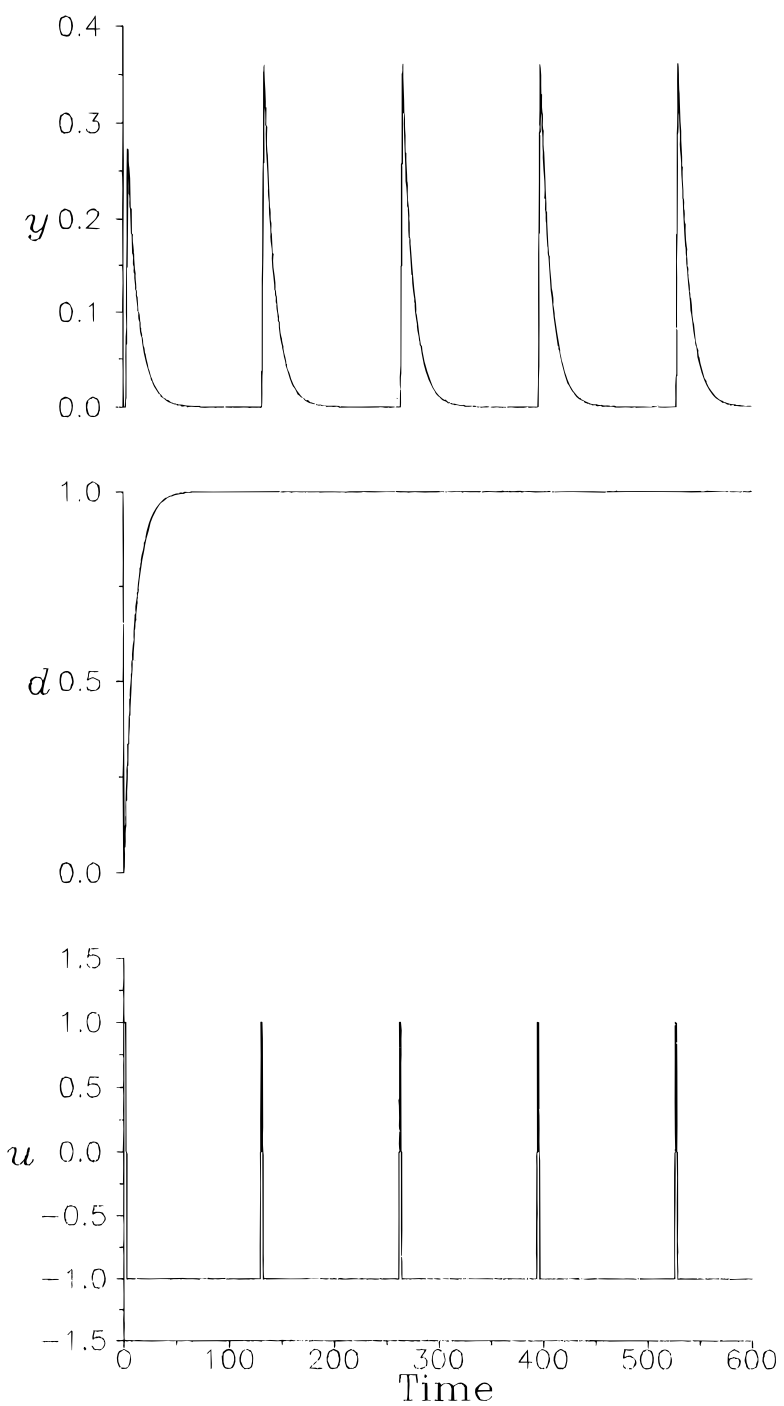

Figure 6. Input-output responses for ideal relay feedback system when the magnitude of load change approaches the upper bound $\left(K_{L} L \rightarrow K_{p} h\right)$ for $G_{1}$.

sustained oscillation.) Taking the limit, the bias term of the Fourier coefficient (eq 16) becomes

$$
A_{0} \rightarrow-h
$$

Furthermore, the rest of the nonzero Fourier coefficients, $A_{2}, A_{4}, \ldots, B_{1}, B_{3}, \ldots$, are approaching zero (eqs 17 and 18). Equation 27 provides another prospective to the limiting condition: it characterizes the manipulated input $(\mathrm{u}(\mathrm{t}))$. Therefore, instead of correlating $\Delta \mathrm{a}$ to the maximum allowable load change $\left(K_{L} L\right)$, the relationship between the manipulated input and largest load change for the existence of a limit cycle is established. A steady-state analysis from the block diagram (Figure 3) indicates that, under this circumstance, the maximum al lowable load change is in balance with the achievable capacity of the manipulated input. That is:

$$
\mathrm{K}_{\mathrm{L}} \mathrm{L}+\mathrm{K}_{\mathrm{p}}(-\mathrm{h})=0
$$

or

$$
\mathrm{K}_{\mathrm{L}} \mathrm{L}=\mathrm{K}_{\mathrm{p}} \mathrm{h}
$$

Let us take the first-order example $\left(\mathrm{G}_{1}\right)$ to illustrate this. Considering the case when $\mathrm{h}=1$ and $\mathrm{L}=0.999999$ $\left(\mathrm{K}_{\mathrm{L}} \mathrm{L}<\mathrm{K}_{\mathrm{p}} \mathrm{h}\right)$, the input-output responses are shown in 
Figure 6. The results indicate that the magnitude of the mani pulated input $(u(t))$ approaches $-h$, while the output $(y)$ stays fairly close to the set point $(y=0)$. Furthermore, if $K_{L} L$ exceeds unity, i.e., $K_{L} L>K_{p} h$, the ideal relay feedback system fails to generate sustained oscillation.

After deriving the relationship between the load effect $\left(K_{L} L\right)$ and corresponding process variables (e.g., $K_{p}$ and h) at these two extremes, a new result can readily be formulated. For linear processes, the linear interpolation can be utilized to correlate the asymmetry $(\Delta a)$ to the load effect $\left(K_{L} L\right)$. From eqs 26 and 29, the slope describing $\Delta a$ and $K_{L} L$ is

$$
\frac{\mathrm{a}-0}{\mathrm{~K}_{\mathrm{p}} \mathrm{h}-0}=\frac{\mathrm{a}}{\mathrm{K}_{\mathrm{p}} \mathrm{h}}
$$

Therefore, the linear relationship relating the asymmetry $\Delta a$ to the load effect becomes

$$
\Delta \mathrm{a}=\frac{\mathrm{a}}{\mathrm{K}_{\mathrm{p}} \mathrm{h}} \mathrm{K}_{\mathrm{L}} \mathrm{L}
$$

or

$$
\frac{\Delta \mathrm{a}}{\mathrm{a}}=\left(\frac{1}{\mathrm{~K}_{\mathrm{p}} \mathrm{h}}\right) \mathrm{K}_{\mathrm{L}} \mathrm{L}
$$

The new result gives a simple description between the load effect and relevant process variables. Again, the three linear examples $\left(G_{1}, G_{2}\right.$, and $\left.G_{3}\right)$ are used to validate eq 32. Figure 7 shows that for the three typical process transfer functions with a load transfer function ( $G_{L}$ in eq 2 ), the asymmetry $\Delta a / a$ is indeed a linear function of the load effect $\left(K_{L} L\right)$. This is the main result (eq 32) in this paper.

Furthermore, with this new equation, we are able to backcalculate the load effect and the steady-state gain. Substituting $K_{L} L$ of eq 32 into eq 25 , the steady-state gain can be solved directly. That gives

$$
\mathrm{K}_{\mathrm{p}}=\frac{-\overline{\mathrm{e}}}{(\Delta \mathrm{a} / \mathrm{a}) \mathrm{h}+\overline{\mathrm{u}}}
$$

Once $K_{p}$ is available, the load effect can be solved from eq 32.

$$
\mathrm{K}_{\mathrm{L}} \mathrm{L}=\left(\frac{\Delta \mathrm{a}}{\mathrm{a}}\right) \mathrm{K}_{\mathrm{p}} \mathrm{h}
$$

Therefore, eqs 33 and 34 can be utilized to find additional process information. Since the objective of this work is to restore a symmetric output response, the use of these two equations will not be elaborated on further.

3.3.2. Opposite Effect from Output-Biased Relay. Similarly, the linear relationship counterpart can be derived for the output-biased rel ay feedback system. Again, from the Fourier analysis, the two extreme conditions for the existence of a limit cycle can readily be derived (Shen, 1995). The lower bound corresponds to:

$$
\delta_{0}=0 \Rightarrow \Delta \mathrm{a}_{0}=0
$$

and the upper bound is

$$
\delta_{0} \rightarrow \mathrm{h} \Rightarrow \Delta \mathrm{a}_{0} \rightarrow \mathrm{a}
$$

Therefore, thelinear relationship for the output-biased
Ind. Eng. Chem. Res., Vol. 35, No. 5, 1996

1647

\section{(A)}

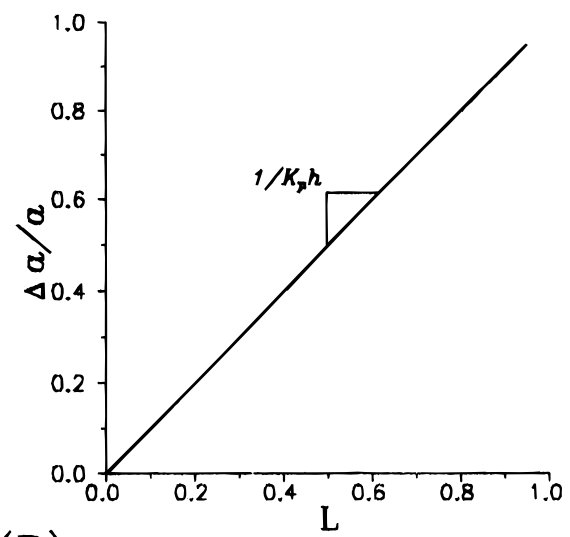

(B)

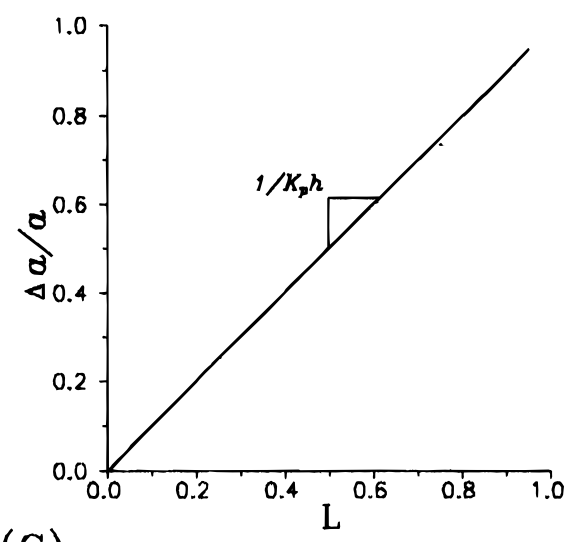

(C)

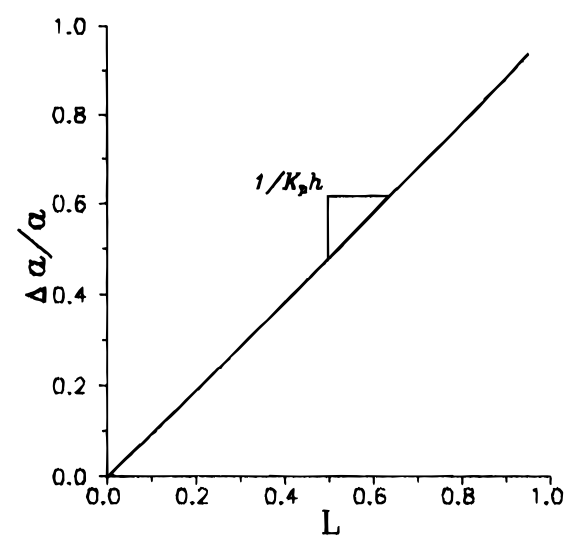

Figure 7. Linear relation between bias value $(\Delta a / a)$ and magnitude of load $(L)$ under ideal relay feedback for $(A)$ first-order $\left(G_{1}\right)$, (B) second-order $\left(G_{2}\right)$, and $(C)$ third-order $\left(G_{3}\right)$ systems.

relay becomes

$$
\frac{\Delta \mathrm{a}_{0}}{\mathrm{a}}=\left(\frac{1}{\mathrm{~h}}\right) \delta_{0}
$$

Actually, eq 37 is the dual of eq 32 , which describes the relationship between the asymmetry in the output response $\left(\Delta \mathrm{a}_{0}\right)$ and the biased value $\left(\delta_{0}\right)$ in the relay.

Since the load change introduces the asymmetry $(\Delta \mathrm{a})$ in $y$, the way to restore the symmetric output response is to switch the relay to an output-biased relay such 
that:

$$
\Delta \mathrm{a}_{0}=-\Delta \mathrm{a}
$$

Therefore, the bias value $\left(\delta_{0}\right)$ can be found immediately (eqs 37 and 38).

$$
\delta_{0}=-\left(\frac{\Delta a}{a}\right) h
$$

This important result gives the bias value $\left(\delta_{0}\right)$ for a better estimate of $\mathrm{K}_{\mathrm{u}}$ and $\omega_{\mathrm{u}}$ throughout the relay feedback test. Without eq 39, one has to go through a trial-and-error procedure to find the correct value of $\delta_{0}$ (Hang et al., 1993a). More importantly, all the variables $(\Delta \mathrm{a}, \mathrm{a}$, and $\mathrm{h})$ needed to compute $\delta_{0}$ can be read off directly from the input-output response.

3.4. Summary of Procedure. Consider an ideal relay feedback system (F igure $3 A$ ). If a load disturbance comes into the system during the plant test, an asymmetric oscillation results. If eqs information about the magnitude of disturbance and steady-state gain is needed, 33 and 34 can be utilized to solve for $K_{p}$ and $K_{L} L$ provided with $\bar{u}$ and $\bar{y}$. Otherwise, the experiment proceeds with an output-biased relay using the bias value computed from eq 39 . Therefore, the procedure can be summarized as follows:

(1) Perform an ideal relay feedback test (Figure 3).

(1a) If the limit cycle is symmetric, then calculate $\mathrm{K}_{\mathrm{u}}$ and $\omega_{\mathrm{u}}$

$$
\begin{aligned}
& \mathrm{K}_{\mathrm{u}}=4 \mathrm{~h} / \pi \mathrm{a} \\
& \omega_{\mathrm{u}}=2 \pi / \mathrm{P}_{\mathrm{u}}
\end{aligned}
$$

and stop the experiment.

(1b) If the limit cycle is asymmetric:

A. When the additional information, steady-state gain and magnitude of load change, is needed, integrate system input and output responses $\bar{u}$ and $\bar{e}$ in eqs 11 and 12 ) find $K_{p}$ and $K_{L} L$ according to eqs 33 and 34 . Notice that, in order to have an accurate esti mate of $K_{p}$ and $K_{L} L$, one has to wait until the asymmetric response settles down. Typically, it takes 2-3 cycling periods.

$B$. If the additional information is not needed, go to step 2.

(2) Perform an output-biased relay feedback test with the bias value (eq 39) of

$$
\delta_{0}^{(1)}=-\frac{\mathrm{h} \Delta \mathrm{a}^{(1)}}{\mathrm{a}^{(1)}}
$$

(2a) If the limit cycle becomes symmetric, then calculate $\mathrm{K}_{\mathrm{u}}$ and $\omega_{\mathrm{u}}$

$$
\begin{aligned}
& \mathrm{K}_{\mathrm{u}}=4 \mathrm{~h} / \pi \mathrm{a} \\
& \omega_{\mathrm{u}}=2 \pi / \mathrm{P}_{\mathrm{u}}
\end{aligned}
$$

and stop the experiment.

(2b) If the limit cycle is still asymmetric, then update the biased value in the output-biased relay according to:

$$
\delta_{0}^{(\mathrm{i}+1)}=\delta_{0}{ }^{(\mathrm{i})}-\frac{\mathrm{h} \Delta \mathrm{a}^{(\mathrm{i})}}{\mathrm{a}^{(\mathrm{i})}}
$$

where $\delta_{0}{ }^{(i+1)}$ stands for the biased value in the $(i+1)$ th adjustment and $\Delta \mathrm{a}^{(\mathrm{i})}$ represents the bias in the output

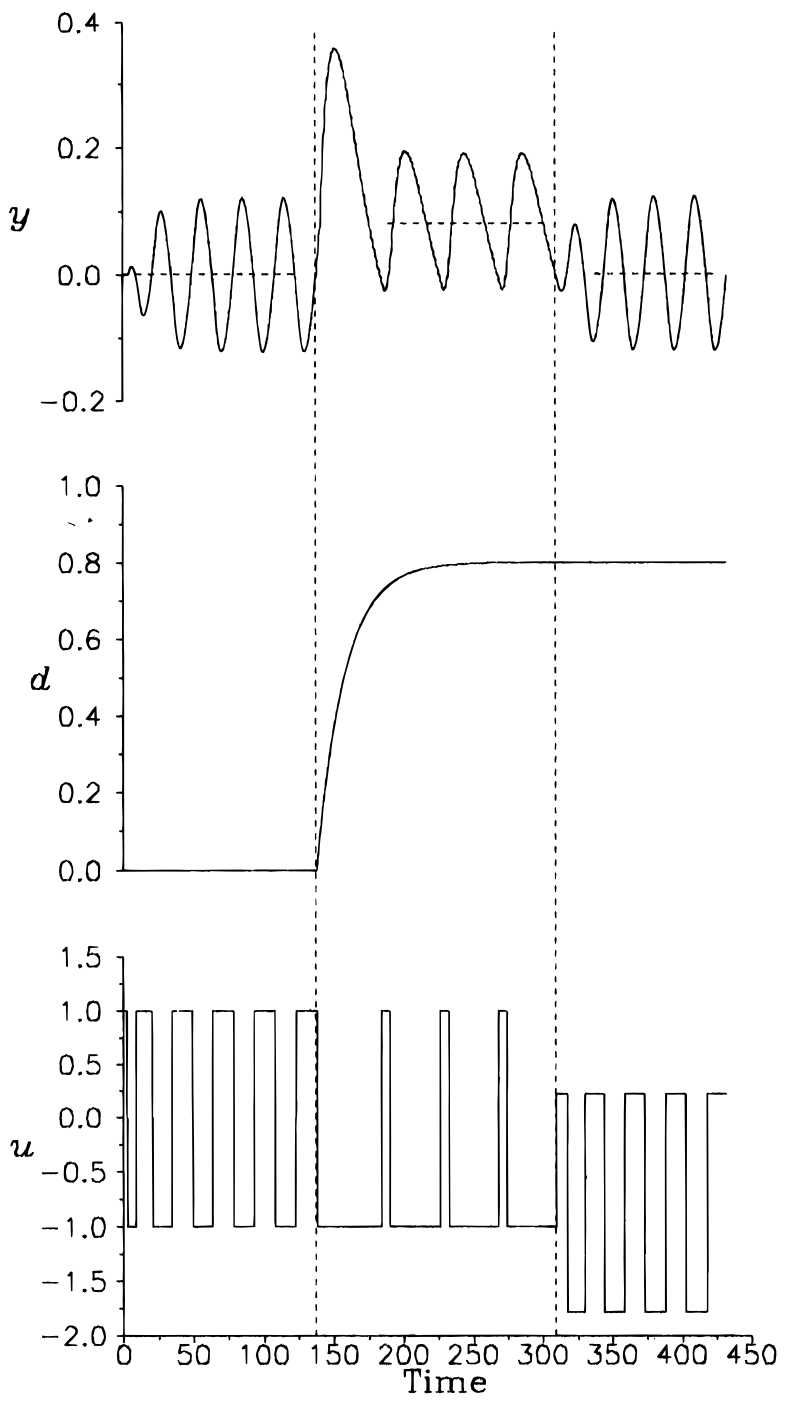

Figure 8. Input and output responses for ideal relay feedback and output-biased relay feedback under a step load change for $\mathrm{G}_{1}$.

with respect to the previous center point. It is recommended that the biased value is updated every $1-2$ oscillations.

\section{Applications}

Linear and nonlinear examples are used to illustrate the effectiveness of the proposed system identification approach under load changes. Step-like and non-steplike of load changes are discussed. The ultimate gain and ultimate frequency are used to evaluate the correctness of the identified model.

4.1. Linear System. Consider a third-order plus dead time system:

$$
\begin{gathered}
G_{3}(s)=\frac{e^{-2 s}}{(20 s+1)(10 s+1)(s+1)} \\
G_{L}(s)=\frac{e^{-s}}{(10 s+1)}
\end{gathered}
$$

Without load disturbance, a relay feedback experiment gives $\mathrm{K}_{\mathrm{u}}=10.44$ and $\omega_{\mathrm{u}}=0.2126(\mathrm{t}=0-140 \mathrm{~min}$ in Figure 8). This corresponds to $-5.6 \%$ and $-2.9 \%$ errors in $\mathrm{K}_{\mathrm{u}}$ and $\omega_{\mathrm{u}}$, respectively. When a step load change with $\mathrm{L}=0.8$ is introduced at $\mathrm{t}=140 \mathrm{~min}$, an asymmetric sustained oscillation results $(t=140-310 \mathrm{~min}$ 
in Figure 8). Again, $\mathrm{K}_{\mathrm{u}}$ and $\omega_{\mathrm{u}}$ can be estimated (eqs 5 and 6), and corresponding errors are $7.46 \%$ and $-31.54 \%$, respectively. Obviously, the quality of the estimates deteriorates as the result of load disturbance. At this point, one can proceed to the step $1 \mathrm{~b}-\mathrm{A}$ to find additional information. From system response, we have $\Delta a=$ 0.08354 and $\mathrm{a}=0.107$, while $\bar{u}$ and $\bar{e}$ can be found by integrating the input $(\mathrm{u}(\mathrm{t}))$ and output $(\mathrm{y}(\mathrm{t}))$. That gives $\overline{\mathrm{u}}=0.09421$ and $\overline{\mathrm{e}}=0.1335$. Subsequently, the steadystate gain and static load effect can be computed from eqs 33 and 34. The results are $K_{p}=1.029$ and $K_{L} L=$ 0.803 which are indeed very good estimates. If the information about $K_{p}$ and $K_{L} L$ is not required, one can go directly to step 2 . With the known values of $\Delta a$ and a, the biased value $\left(\delta_{0}\right)$ can be computed from eq 39, and the result becomes $\delta_{0}=0.78$. Next, an outputbiased relay feedback test is performed ( $t>140$ in Figure 8), and $K_{\mathrm{u}}$ and $\omega_{\mathrm{u}}$ can be found. That gives $\mathrm{K}_{\mathrm{u}}$ $=10.44$ and $\omega_{\mathrm{u}}=0.2126$, which are exactly the same as that of the disturbance-free case. Therefore, the example clearly shows that, incorporated with eq 39, the output-biased relay is very effective in maintaining the quality of the model in the face of load changes.

Despite the fact that chemical processes often face progressive types of load disturbance, in several occasions, non-step-like load changes come into process units. Again, the proposed method is tested against a series of step changes. For the third-order example, Figure 9 (middle line) shows the load changes. Once the asymmetry in the output is detected (F igure 9), the biased value $\left(\delta_{0}\right)$ is adjusted at the end of each cycling period according to eq 40 . Despite the fact that the oscillation hardly settles down (Figure 9), the estimates of $K_{u}$ and $\omega_{u}$ can still be very accurate. Table 1 shows the estimated $K_{u}$ and $\omega_{u}$ every $3-4$ periods. The results clearly indicate that the proposed method can identify a quality model under nonstationary load disturbance.

4.2. Binary Distillation Column. Since the asymmetry in the output response can come from load change as well as process nonlinearity, the proposed approach is tested on a nonlinear process under load change. A binary distillation column (Shen and Yu, 1992) is used to illustrate the effectiveness of the proposed approach. This is a 20-tray distillation column. The product specifications are $98 \%$ and $2 \%$ light component on the top and bottoms, respectively. The relative volatility is 2.26 with a reflux ratio of 1.76. Table 2 gives the steady-state values. The control objective is to maintain the top and bottoms product compositions ( $X_{D}$ and $X_{B}$ ) by changing the reflux flow rate $(R)$ and vapor boilup rate $(\mathrm{V})$. This is the conventional $\mathrm{R}-\mathrm{V}$ control structure (Figure 10). In the nonlinear simulation, the following assumptions are made: (1) equal molar overflow; (2) $100 \%$ tray efficiency; (3) saturated liquid feed; (4) total condenser and partial reboiler; and (5) perfect level control. An analyzer dead time of 6 min is used for top and bottoms composition measurements.

For this moderate purity column, the stepping technique (Luyben, 1990) is used to find the ultimate gain and ultimate frequency at the nominal operating point. That gives $K_{\mathrm{u}}=802.7$ and $\omega_{\mathrm{u}}=0.138$ for the $\mathrm{X}_{\mathrm{D}}-\mathrm{R}$ loop. First, an ideal relay feedback test is performed on the $\mathrm{X}_{\mathrm{D}}-\mathrm{R}$ loop, and the results are $\mathrm{K}_{\mathrm{u}}=736$ and $\omega_{\mathrm{u}}=0.132$ $(t=0-210 \mathrm{~min}$ in Figure 11). At $\mathrm{t}=210 \mathrm{~min}, \mathrm{a}-5 \%$ step change in feed flow rate is introduced, and this leads to an asymmetric oscillation (Figure 11). The estimates of $K_{u}$ and $\omega_{u}$ become 705.5 and 0.112 , respectively. As the result of the feed flow rate disturbance,
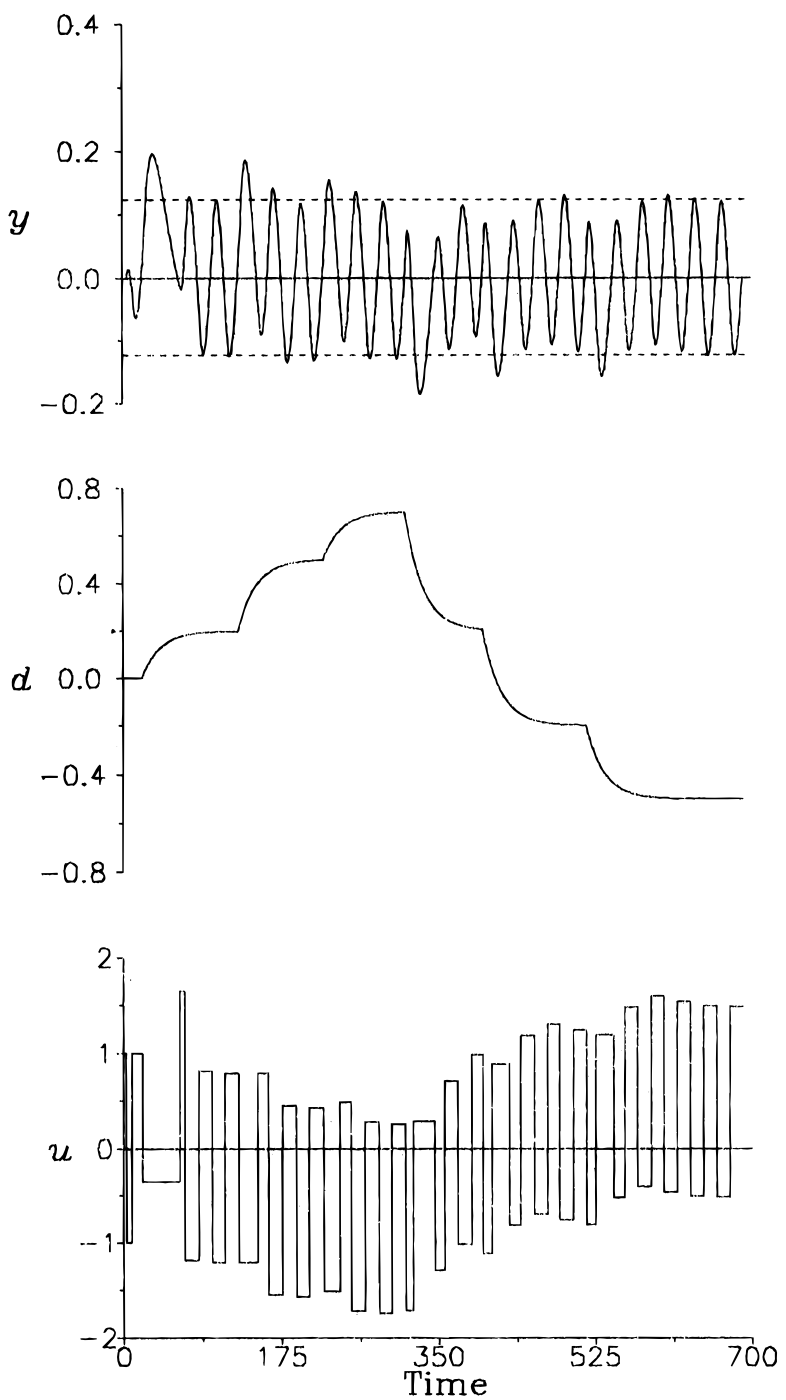

Figure 9. Input and output responses for the proposed outputbiased relay feedback under a series of step load changes for $G_{1}$.

Table 1. Estimated $\mathrm{K}_{\mathrm{u}}$ and $\omega_{\mathrm{u}}$ under a Series of Step Load Changes at Different Periods of Oscillation

\begin{tabular}{ccc}
\hline period of oscillation & $\mathrm{K}_{\mathrm{u}}$ & $\omega_{\mathrm{u}}$ \\
\hline 3 & 10.20 & 0.2080 \\
7 & 10.23 & 0.2102 \\
10 & 10.25 & 0.2107 \\
14 & 10.46 & 0.2125 \\
17 & 10.25 & 0.2106 \\
22 & 10.21 & 0.2105
\end{tabular}

Table 2. Steady-State Values for the Binary Distillation Columns

\begin{tabular}{lc}
\multicolumn{1}{c}{ parameters } & value \\
\hline no. of trays & 20 \\
feed tray & 10 \\
relative volatility & 2.26 \\
operating pressure $(\mathrm{atm})$ & 1.0 \\
feed flow rate $(\mathrm{kg} \cdot \mathrm{mol} / \mathrm{min})$ & 36.3 \\
distillate flow $\mathrm{rate}(\mathrm{kg} \cdot \mathrm{mol} / \mathrm{min})$ & 18.15 \\
bottoms flow rate $(\mathrm{kg} \cdot \mathrm{mol} / \mathrm{min})$ & 18.15 \\
reflux ratio & 1.76 \\
feed composition $(\mathrm{mole}$ fraction) & 0.50 \\
distillate composition (mole fraction) & 0.98 \\
bottoms composition (mole fraction) & 0.02
\end{tabular}

the estimation error in $\mathrm{K}_{\mathrm{u}}$ increases from $8 \%$ to $12 \%$ and the error in the estimate of $\omega_{\mathrm{u}}$ increases from $4 \%$ to $19 \%$. From system response (F igure 11 ), the parameters a and $\Delta a$ can be read off immediately and the biased value of the output-biased relay can be calculated 


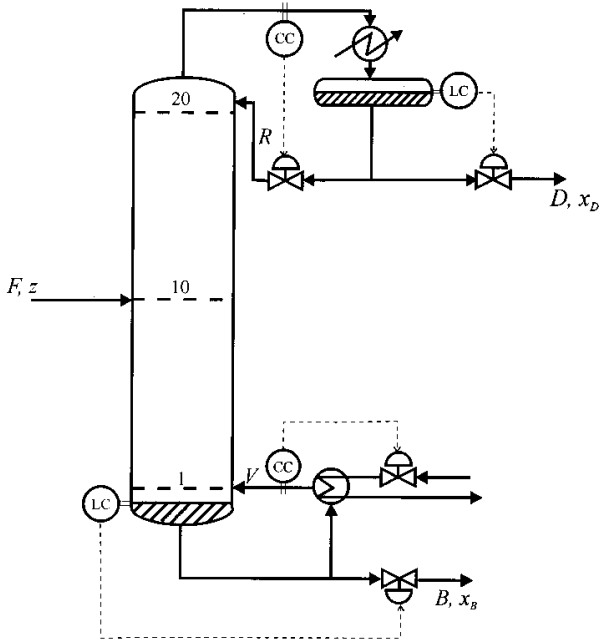

Figure 10. Distillation column under $\mathrm{R}-\mathrm{V}$ control.

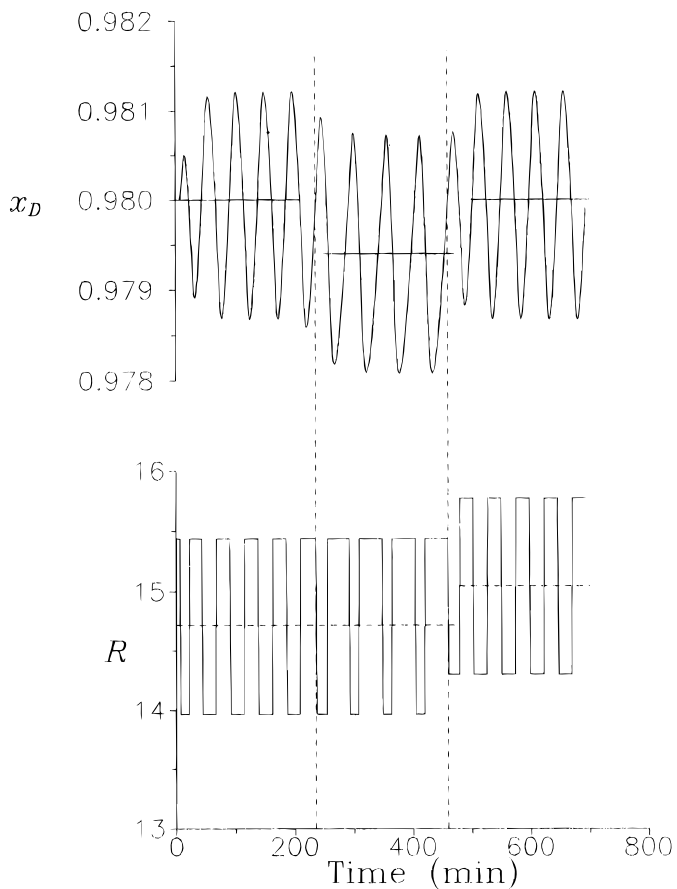

Figure 11. Input and output responses for ideal relay feedback and output-biased relay feedback under $a+5 \%$ step feed flow rate change for the distillation example.

accordingly $\left(\delta_{0}=0.3328\right)$. Therefore, the relay feedback test continues with an output-biased relay. The results show that (t $>450$ min in shenflow) symmetric output response is restored and the estimates of $\mathrm{K}_{\mathrm{u}}$ and $\omega_{\mathrm{u}}$ become 734.5 and 0.131 , respectively. The results indicate that, under load disturbance, a better estimate of $\mathrm{K}_{\mathrm{u}}$ and $\omega_{\mathrm{u}}$ can be achieved using the output-biased relay. More importantly, the remedial action can be made by simply observing input-output response.

\section{Conclusion}

Load disturbance can lead to erroneous results in system identification. This is typically troublesome during the plant test for slow chemical processes. Despite the fact that the relay feedback test is more resilient to load changes, as the magnitude of load change increases, the estimates of $\mathrm{K}_{\mathrm{u}}$ and $\omega_{\mathrm{u}}$ deteriorate exponentially. Since external load disturbance can lead to an asymmetric oscillation in system output, an intuitive approach to maintain the quality of the model is to restore a symmetric output response. The causes of error are analyzed using the describing function, and an output-biased relay is proposed to elimi nate the bias in the system output. Furthermore, a new relationship is derived to find the biased value in a straightforward manner. Finally, an autotune identification procedure is proposed for system identification under load changes. The proposed approach is tested against linear and nonlinear distillation examples. The results show that good estimates of $\mathrm{K}_{\mathrm{u}}$ and $\omega_{\mathrm{u}}$ can be achieved under steplike as well as non-step-like load changes.

\section{Notation}

$a=$ amplitude of the limit cycle

$A_{0}=$ Fourier coefficient of the constant term

$A_{n}=$ Fourier coefficient of the sine wave term

ATV = autotune variation

$B_{n}=F$ ourier coefficient of the cosine wave term

DIDF = dual-input describing function

$\mathrm{G}(\mathrm{s})=$ process transfer function

$\mathrm{G}_{\mathrm{L}}(\mathrm{s})=$ load transfer function

$\mathrm{h}=$ magnitude of the relay output

$\mathrm{K}_{\mathrm{L}}=$ steady-state gain of the load transfer function

$K_{p}=$ steady-state gain

$\mathrm{K}_{\mathrm{u}}=$ ultimate gain

$\mathrm{L}=$ load variable

$\mathrm{N}=$ describing function for the oscillatory part

$\mathrm{N}_{\gamma}=$ describing function for the static part

$\mathrm{NL}=$ nonlinear element

$\mathrm{P}_{\mathrm{u}}=$ period of the limit cycle

$\mathrm{R}=$ reflux flow rate

$\mathrm{s}=$ Laplace transform variable

$\mathrm{u}=$ system input (output of relay)

$\mathrm{V}=$ vapor boilup rate

$\mathrm{X}_{\mathrm{D}}=$ distillate composition

$\mathrm{X}_{\mathrm{B}}=$ bottoms composition

$\mathrm{y}=$ system output (input to relay)

$y^{\max }=$ maximum value in the system output

$y^{\min }=$ minimum value in the system output

Greek Letters

$\alpha=$ relative volatility

$\Delta \mathrm{a}=$ bias in the system output for ideal relay feedback test

$\Delta a_{0}=$ bias in the system output for output-biased relay feedback test

$\delta_{0}=$ biased value in output-biased relay

$\omega_{\mathrm{u}}=$ ultimate frequency

\section{Literature Cited}

Atherton, D. P. Nonlinear Control Engineering; Van Nostrand Reinhold: London, 1982.

Åström, K.J .; Hägglund, T. Automatic Tuning of Simple Regulators with Specifications on Phase and Amplitude Margins. Automatica 1984, 20, 645.

Åström, K. J .; Hägglund, T. PID Controllers: Theory, Design, and Tuning, 2nd ed.; Instrument Society of America: Research Triangle Park, NC, 1995.

Friman, M.; Waller, K. Autotuning of Multiloop Control Systems. Ind. Eng. Chem. Res. 1994, 33, 1708.

Hang, C. C.; Åström, K. J .; Ho, W. K. Relay Auto-Tuning in the Presence of Static Load Disturbance. Automatica 1993a, 29, 563.

Hang, C. C.; Lee, T. H.; Ho, W. K. Adaptive Control; Instrument Society of America: Research Triangle Park, NC, 1993b.

Luyben, W. L. Derivation of Transfer Functions for Highly Nonlinear Distillation Columns. Ind. Eng. Chem. Res. 1987, 26, 2490.

Luyben, W. L. Process Modeling, Simulation and Control for Chemical Engineers, 2nd ed.; McGraw-Hill: New York, 1990.

Luyben, W. L.; Eskinat, E. Nonlinear Auto-Tune Identification. Int. J . Control 1994, 59, 595. 
Marlin, T. E. Process Control: Designing Processes and Control Systems for Dynamic Performance; McGraw-Hill: New York, 1995.

Oldenburger, R.; Boyer, R. C. Effects of Extra Sinusoidal Input to Nonlinear Systems. Trans. ASME 1962, 84D, 559.

Rivera, D. E.; Pollard, J. F.; Garcia, C. E. Control-Relevant Prefiltering A Systematic Design Approach and Case Study. IEEE Trans. Autom. Control 1992, 37, 964.

Seborg, D. E.; Edgar, T. F.; Mellichamp, D. A. Process Dynamics and Control; J ohn Wiley \& Sons: New York, 1989.

Shen, S. H. Use of Relay Feedback Test for System I dentification. Ph.D. Dissertation, National Taiwan Institute of Technology, Taipei, Taiwan, R.O.C., 1995.

Shen, S. H.; Yu, C. C. Indirect Feedforward Control: Multivariable Systems. Chem. Eng. Sci. 1992, 47, 3085.

Shen, S. H.; Yu, C. C. Use of Relay-Feedback Test for Automatic Tuning of Multivariable Systems. AIChE J . 1994, 40, 627.

Shen, S. H.; Wu, J . S.; Yu, C. C. Biased-Relay Feedback for System Identification. AlChE J. 1995, in press.

Shook, D. S.; Mohtad, C.; Shah, S. L. A Control-Relevant Identification Strategy for GPC. IEEE Trans. Autom. Control 1992 $37,975$.
Smith, C. L. Digital Computer Process Control; Intex: Scranton, PA, 1972.

West, J . C.; Douce, J . L.; Livesley, R. K.The Dual-Input Describing Function and Its Use in the Analysis of Non-linear Feedback Systems. Proc. IEE 1956, 103B, 463.

Wu, W. T.; Tseng, C. G.; Chu, Y. T. System I dentification and Online Robust Control of a Multivariable System. Int. J . Syst. Sci. 1994, 25, 423.

Ziegler, J .; Nichols, N. Optimum Settings for Automatic Controllers. Trans. ASME 1942, 759-768.

Received for review J uly 31, 1995

Revised manuscript received J anuary 4, 1996

Accepted J anuary 31, 1996 ${ }^{\circledR}$

IE950480G

${ }^{\otimes}$ Abstract published in Advance ACS Abstracts, March 15, 1996. 